\title{
Strategic Interaction among Governments in the Provision of a Global Public Good*
}

\author{
Margaret K. Kyleł David B. Ridley
}

October 15, 2017

\begin{abstract}
How do governments respond to other governments when providing a global public good? Using data from 2007-2014 on medical research funding for infectious and parasitic diseases, we examine how governments and foundations in 41 countries respond to funding changes by the US government (which accounts for half of funding for these diseases). Because funding across governments might be positively correlated due to unobserved drivers they have in common, we use variation in the representation of research-intensive universities on US Congressional appropriations committees as an instrument for US funding. We find that a 10 percent increase in US government funding for a disease is associated with a 2 to 3 percent reduction in funding for that disease by another government in the following year.
\end{abstract}

${ }^{*}$ This is a preprint of an article appearing in the Journal of Public Economics. We are grateful for helpful comments from James Anton, Peter Arcidiacono, Ashish Arora, Victor Bennett, Ernst Berndt, Thomas Buchmueller, Thomas Nechyba, Dana Randall, Shannon Seitz, and Ariel Stern, as well as conference and seminar participants at INSEAD, the European Health Economics Association, the International Industrial Organization and Journée de la Chaire Santé at Université Paris Dauphine. Margaret Kyle received support from the Health Chair - a joint initiative by PSL, Université Paris-Dauphine, ENSAE, MGEN and ISTYA under the aegis of the Fondation du Risque (FDR).

$\dagger$ MINES ParisTech (CERNA), PSL Research University, and CEPR

${ }^{\ddagger}$ Corresponding author: David Ridley, Fuqua School of Business, Duke University, Durham, NC 27708, david.ridley@duke.edu, +1.919.660.3784.

${ }^{\S}$ Department of Economics, Duke University 


\section{Introduction}

Knowledge generated by a firm's research and development (R\&D) activities can be a public good, limiting the ability of the firm to fully appropriate the benefits of its investment (?). As a result, firms tend to invest less money than is socially optimal. To correct for the market failure, governments use patents, innovation prizes, R\&D tax credits, and direct funding of R\&D through grants. The resulting innovation or knowledge can cross national borders, potentially causing other governments to alter their own innovation policies. We examine whether spending on basic medical research by one government affects spending by others. Economic theory suggests that it should (???), but we have little evidence for this phenomenon outside of national defense spending (??) and environmental regulation (?).

This is the first economic analysis to investigate whether governments respond strategically to one another in funding basic medical research. We focus on infectious and parasitic diseases because of the enormous impact of the diseases on human welfare. 11 We have data on research funding for 15 infectious and parasitic diseases across 41 countries and organizations from 2007 to 2014 collected annually by the non-profit Policy Cures. We are not aware of a similarly comprehensive source of medical research funding data for other diseases.

Identifying a strategic response by a funder is not straightforward. Two funders might experience the same economic shock to their budgets and adjust funding in the same direction. Also, two funders might prioritize the same diseases if they both consider disease burden or scientific productivity. To identify a strategic response, we need an exogenous shock to one budget to observe the response by other funders. We use the composition of United States (US) Congressional appropriations committees as an instrumental variable to address the endogeneity of government research funding. The US National Institutes of Health (NIH) accounted for more than half of global government and non-profit research funding for infectious and parasitic diseases between 2007 and 2014. Congress sets the NIH budget annually, and the budget fluctuates as the composition of Congress changes. When Congressional appropriations committees have more members representing research-intensive universities, US government research outlays tend to be higher. This exogenous change allows us to test whether other governments adjust their spending in response.

\footnotetext{
${ }^{1}$ Infectious diseases were four of the top five priorities (nutrition being the fifth) for the Copenhagen Consensus III of 2012, during which an expert panel, including four Nobel laureates, set priorities for advancing global welfare (http://www. copenhagenconsensus.com/copenhagen-consensus-iii/outcome). Furthermore, with a philosophy of every life having equal value and of evidence-driven investment, the Gates Foundation - the largest in the world - spends most of its resources on medical care, especially in the infectious and parasitic disease areas.
} 
We find that a 10 percent increase in US government outlays for medical research is associated with a 2 to 3 percent decrease in outlays by other funders (i.e., other government agencies or non-governmental organizations [NGOs]) in the following year. We also find that changes in US funding for a given disease typically influence other funders only if the other funders are already funding the disease. Government agencies tend to fund diseases with a high local burden and respond to US outlays more intensely for such diseases. In contrast, it is rare for a government agency to stop funding a disease entirely in response to an increase in US outlays, or begin funding a new disease in response to a decrease in US outlays. In other words, changes in US outlays primarily affect the intensive margin rather than the extensive margin for other funders.

The negative relationship between US government funding for a disease and funding by other governments, NGOs, and foundations is consistent with free riding. According to the World Health Organization:

"Failure to provide global public goods is linked to collective action problems such as 'free-riding.' The free-rider term describes a situation when no individual is prepared to pay the cost of something that others may be expected to benefit from; instead, all hope that someone else will pay for it and they will benefit for free. This is particularly an issue for research and development $(\mathrm{R} \& \mathrm{D})$ into medicines to combat neglected diseases, which requires high-levels of investment." (?)

Free riding is not the only explanation for this relationship, however. A negative relationship in funding outlays is also consistent with optimal reallocation. We cannot distinguish between the two. Regardless of whether we refer to it as free riding, optimal reallocation, or crowding out, it is important to be aware that when the US government increases outlays for research on a disease by one dollar, the global increase (net of foreign reductions) is smaller. We estimate an increase in net international outlays of $\$ .70$ to $\$ .80$ when the US government allocates one additional dollar to research on a disease.

\section{Related literature}

US drug makers and government officials sometimes complain that when other countries cap drug prices, they are free riding on the US market (?). They argue that high prices in the US provide the demand that encourages much commercial drug development. However, 
despite largely unregulated drug prices, US-based firms or inventors are not disproportionately responsible for new molecular entities (?). However, with low trade and knowledge barriers, the location of invention may be irrelevant. What matters, rather, is the global profit potential that a firm expects, and this should not depend on the country in which the firm has its headquarters or operates a research laboratory.

The potential for free riding is one justification for the expansion of intellectual property requirements in international trade agreements; that is, each country would prefer other countries to provide patent protection to induce innovation. While intellectual property rights can reduce free riding and improve patient welfare in the long run, patient welfare can diminish in the short run due to rising drug or vaccine prices (?), especially for new products with little competition (?). Furthermore, even diseases prevalent around the world will not receive much commercial investment if nearly all of the people suffering from the diseases live in poor countries (?). Intellectual property rights might be ineffective as an incentive mechanism to support medical research funding for such diseases, and thus motivate government, NGO, or foundation research funding. In contrast to discussion about intellectual property rights, there has been relatively little discussion of how national policies on research funding may be subject to free riding or require coordination. This is the first study to examine strategic interaction among governments in funding basic medical research.

Government R\&D funding has been shown to crowd out private investment. Government R\&D funding can crowd out private funding if government funding bids up the wages of scientists and engineers, which makes private investment in innovation more expensive (?). Conversely, government funding can complement private investment if governments invest in early-stage research, while private investors fund later-stage development (??). The complementarity of government research and private development for medical research funding has been more evident for early stage (Phase I) clinical trials rather than later, costlier (Phase III) trials (?). However, it is difficult to find a clean econometric experiment to identify these effects (?).

In addition to investment crowd out, government funding may affect private charity spending (?). During the Great Depression, government charitable programs expanded, while private charities reduced funding for the poor and instead devoted funding to other causes (??). ? recommended that governments consider the role of charities in scientific funding: "In determining their own funding strategies, they must no longer assume that their funding is the only source in shaping some fields of research while recognizing that philanthropy may ignore other important fields." Outside of medical research, previous work has examined 
how government funding affects the private provision of health insurance. Private health insurance coverage fell following the Medicaid expansions between 1987 and 1992 (?) and between 1996 and 2002 (?). With public provision of health insurance, a smaller share of employees adopted employer-based insurance, and employers were less generous in providing insurance.

Governments also interact strategically at the local and state levels (?). Spending across neighboring state governments is positively correlated, perhaps due to herding (?). Furthermore, tax policy is positively correlated between neighboring local governments due to competition for mobile capital (?). In contrast to the positive correlation found in these contexts, we find a negative correlation in spending across governments when accounting for endogeneity, suggesting that R\&D spending is a public good.

Although medical research is supplied and used globally, most previous studies have focused on NIH funding because the NIH is the largest funder of US medical research and because the US government makes NIH data available. However, one shortcoming of analyzing only NIH data is the possibility of biased estimates depending on whether other public spending is positively or negatively correlated with NIH funding outlays. If other governments devote resources to diseases in a pattern similar to that of the NIH, and if we omit the contribution of funding from other governments, then we will overestimate the effect of NIH spending. However, if an increase in spending by the NIH for a particular disease triggers a reduction by other public funders, then we will underestimate the effect of NIH spending. Scientific research is global and scientific efforts across countries surely influence one another, either as complements or substitutes. For example, when the George W. Bush administration prohibited federal funding for the development of and research on new human embryonic cell lines, US researchers increased collaboration with international researchers (?). One implication of our paper is to highlight the importance of accounting for strategic interactions when assessing the productivity of research funding in a single country.

\section{Theory}

Governments and foundations allocate R\&D funding based on health needs and scientific opportunity. According to NIH leaders, "NIH believes that a process that includes multiple measurements of public health needs, but is also informed by scientific opportunity, allows us to fund the best science" (?). Hence, we model outlays as a function of disease burden and scientific knowledge (?). 
We extend the previous framework by including multiple funders and a strategic response by smaller funders to the largest funder. For example, a European government funder might consider outlays by the NIH when choosing to fund a given disease. After all, knowledge generated by NIH-funded research is generally not restricted to the US population, because $\mathrm{NIH}$ policy requires recipients of NIH grants to make their papers available at no cost to the public ${ }^{2}$

Funder $f$ chooses outlays $x_{d}^{f}$ for disease $d$ based on the disease burden that can be alleviated $B_{d}^{f}$, scientific knowledge $S_{d}$, and the funder's budget $Y^{f}$. A funder distributes outlays between research that benefits people globally $x_{d}^{f}$ and outside activities that are strictly local to the funder $o^{f}$. The probability of developing a new treatment is $p\left(\sum_{f} x_{d}^{f}, S_{d}\right)$ which is increasing in scientific knowledge $S$ and concave in the outlay $x \bigsqcup^{3}$

The expected benefit to funder $f$ of outlay $x_{d}^{f}$ is the probability of discovery $p$ multiplied by the disease burden alleviated $B_{d}^{f}$. The benefit to a funder includes other funders' outlays, but not other funders' disease burdens. Therefore, the optimization problem for a funder is:

$$
\begin{gathered}
\max _{x_{d}^{f}} \sum_{d} B_{d}^{f} p\left(x_{d}^{f}, S_{d}\right)+h\left(o^{f}\right) \\
\text { s.t. }: \sum_{d} x_{d}^{f}+o^{f}=Y^{f}
\end{gathered}
$$

In the appendix, we employ a simple model with two periods and two funders, one of which is a dominant funder (for example, the NIH). We solve for comparative statics and generate three testable hypotheses.

We predict that outlays will be positively correlated with disease burden and scientific knowledge, though outlays will not necessarily be proportional to disease burden and scientific knowledge.

Hypothesis 1 Diseases tend to receive greater outlays from a funder if there is a greater disease burden, if there is more scientific knowledge, and if the funder has a larger budget.

Formally, $\partial x_{d}^{f *} / \partial B_{d}^{f}>0, \partial x_{d}^{f *} / \partial S_{d}>0$, and $\partial x_{d}^{f *} / \partial Y^{f}>0$.

The remaining hypotheses concern how outlays by one funder influence funding by another funder.

\footnotetext{
${ }^{2}$ See NIH Public Access Policy

${ }^{3} \mathrm{We}$ assume funders have the same scientific productivity for the same disease regardless of which funder it is. Approximately 90 percent of the outlays in our sample come from the US, the United Kingdom (UK), and France, and we think it is a reasonable assumption for this set of countries. Our assumption may be less valid for countries with a more limited pool of scientific talent.
} 
Hypothesis 2 Greater outlays for a disease by one funder will reduce outlays for the disease by another funder.

Formally, for dominant funder $f$ and a fringe funder $i, \partial x_{d}^{f *} / \partial x_{d}^{i *}<0$. If the dominant funder increases outlays for a disease, fringe funders reduce outlays. The fringe funders spend more on other diseases and on the local (outside) good as described below.

Hypothesis 3 Greater outlays for a disease by one funder increase outlays by the other funder for other purposes, including other diseases and the local (outside) good.

Formally, $\partial x_{d^{\prime}}^{f *} / \partial x_{d}^{i *}>0$ and $\partial x_{o}^{f *} / \partial x_{d}^{i *}>0$. When the dominant funder increases funding for a disease and the other funder reduces funding (Hypothesis ??), some of the funding goes to the local (outside) good and we might characterize it as free riding. However, some of the funding goes to other diseases. Hence, if the dominant funder "over funds" a disease (perhaps due to political pressure), then other funders shift resources to other diseases.

These three hypotheses motivate our empirical examination. One of our challenges is that there could be positive correlation in outlays across funders due to unobserved factors such as taste or mismeasurement in our disease burden and scientific knowledge data. We need a shock to one funder's budget to motivate this funder to change its outlays (Hypothesis ??) so that we can observe the change in the other funder's outlays (Hypothesis ??). We will not directly estimate whether governments are maximizing social welfare, but we will demonstrate how governments respond to one another.

\section{Methods}

Our unit of observation is a disease-funder-year. The model includes both US and global disability-adjusted life years (DALYs) as measures of disease burden, as well as scientific publications. Recall that NIH leaders wrote that "NIH believes that a process that includes multiple measurements of public health needs, but is also informed by scientific opportunity, allows us to fund the best science." Furthermore, "NIH funding levels relate to US and global deaths and disability-adjusted life years (DALYs) - a measure that quantifies the number of healthy years of life lost due to morbidity or premature mortality caused by disease" (?).

\subsection{Identification}

Two factors bias against finding a negative relationship between outlays across funders. The first identification challenge is that if the same unobserved factors motivate funders, 
then outlays across funders might move together. We control for common drivers, such as scientific publications, global burden of a disease, and national income. However, unobserved factors could motivate greater spending by both US and non-US funders. We need an instrumental variable that shifts US funding for a given disease in a given year but that does not directly change funding by non-US agencies, only affecting their funding indirectly through US funding.

Our instrumental variables strategy uses the political composition of the US Congress, which sets the overall NIH budget in addition to setting other global health priorities $4^{4}$ Changes in Congressional committee chairmanships influence total federal spending (?). Likewise, Congressional representation affects medical research funding. Previous work has documented the importance of academic earmarks, which are budgetary carve-outs by members of Congress directed to specific institutions located in their districts (?). Researchers located in districts represented by members of the US House Appropriations Committee received more NIH grants than those without such representation (??) ${ }^{5}$

The validity of our approach rests on the assumption that US political forces that shift NIH funding through changes in the composition of Congressional appropriations committees are unrelated to funding decisions in other countries. That is, the appointment to the House appropriations committee of a representative from a state with a large number of research-intensive universities (who then argues for a larger NIH budget to benefit the local constituency) is independent of the budgetary and funding choices in other countries. If our approach does not adequately address the identification challenge, then our estimates will underestimate the negative correlation and thus the strategic response of non-US funders. For example, if all countries change political control in the same direction, then funding across countries will be positively correlated. Hence, our estimates could be a lower bound.

The second identification challenge is that many funders have small budgets. They often spend nothing on a given disease and thus are limited in how they can respond to an increase in US outlays for that disease (i.e., they cannot spend less than zero). We therefore include a specification that focuses on the intensive margin, or changes conditional on spending

\footnotetext{
${ }^{4}$ See ? for an overview.

${ }^{5}$ A "committee on committees" for each party determines membership on Congressional committees. The committee gives priority to more senior members. New members are given priority according to past service in Congress or as governor. Other new members are sorted by random drawing. Members are generally not permitted to serve on multiple powerful committees. For example, a Senator serving on the Appropriations committee would give up her position in order to receive a position on the Armed Services committee. The committee membership recommendations are voted on within the party, and then in a simple resolution by all members.
} 
anything, as well as a specification that looks only at the decision to allocate any funding at all. Again, our estimates might underestimate the effect and be a lower bound.

\subsection{Estimation}

We estimate outlays from a non-US funder $f$ for a disease $d$ in year $t$ with the following specification:

$$
\begin{aligned}
& \log _{\text {Non-US Funder Outlay }}^{d, f, t}=\beta_{0}+\beta_{1} \log \text { US Outlay }_{d, t-1} \\
& \beta_{2} \log \text { Local Disease } \text { Burden }_{d, c, t}+ \\
& \beta_{3} \log \text { Disease Burden in Poor } \text { Countries }_{d, t}+
\end{aligned}
$$

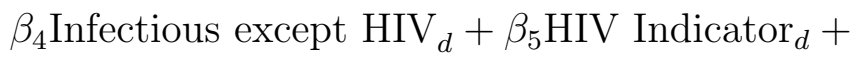

$$
\begin{aligned}
& \beta_{6} \log \text { Number of Publications to } \text { Date }_{d, t}+ \\
& \beta_{7} \log \operatorname{GDP}_{c, t-1}+\phi_{f}+\epsilon_{d, f, t}
\end{aligned}
$$

The explanatory variables include the disease burden, scientific knowledge, and other control variables. The burden of disease in poor countries is net of the local burden for the disease, where poor countries are defined as those listed as low income and lower-middle income by the World Bank $!^{6}$ We measure scientific knowledge as the number of scientific publications to date. We also control for whether the disease is infectious or parasitic. Because HIV is unique in its global and rich-world disease burdens, as well as the medical research funding it has received, we include a separate indicator for HIV. Finally, we include a funder fixed effect to account for time-invariant heterogeneity across funders.

Our main variable of interest is lagged US funding, which might depend on unobserved factors that also drive non-US funding decisions, as discussed previously. We address this endogeneity using two-stage least squares, where the first stage is:

\footnotetext{
${ }^{6}$ http://data.worldbank.org/country
} 


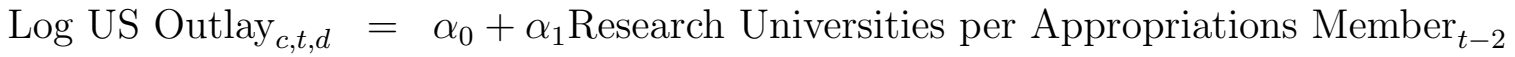

$$
\begin{aligned}
& +\alpha_{2} \log \text { Local Disease Burden }{ }_{d, c, t} \\
& +\alpha_{3} \log \text { Disease Burden in Poor Countries }{ }_{d, t} \\
& +\alpha_{4}{\text { Infectious except } \mathrm{HIV}_{d}+\alpha_{5} \text { HIV Indicator }}_{d} \\
& +\alpha_{6} \log \text { Number of Publications to Date } \text { D }_{d, t} \\
& +\alpha_{7} \log \mathrm{GDP}_{c, t}+\phi_{f}+\epsilon_{d, c, t}
\end{aligned}
$$

In the first stage, the dependent variable is the annual US outlay for disease $d$ in year $t$. We transform the dependent variable into logs (plus one because many of the observations are zero). The instrumental variables we exclude from the second stage are the number of research-intensive universities represented by Congressional appropriations committee members.

The assumed timing in our analysis is as follows. The composition of the Congressional appropriations committees in year $t$ influences the NIH budget in the next fiscal year, $t+1$. Researchers submit proposals and the NIH selects recipients, with allocations beginning in $t+2$. Other governments observe the NIH budget and funding decisions in $t+1$, choose recipients for their funding in $t+2$, and make outlays in $t+3$.

We also estimate alternative specifications. In one specification, we include not only other non-US government agencies but also NGOs and private foundations. The approach is the same as that described above, except with more observations. In another specification, we add an interaction term between the local disease burden and US outlays. In this way, we examine whether government agencies were more responsive to US outlays for diseases with a heavy local burden. This allows us to use the heterogeneity in disease burden across countries to examine responses to US outlays at the intensive margin. To examine responses at the extensive margin, we replace the magnitude of a government agency's outlays with an indicator variable for whether the agency has any outlay for that disease. We include five other specifications to test the robustness of our results. We describe the robustness checks in Section ?? and include the tables in the appendix. 


\section{Data}

To study how governments interact in medical R\&D outlays, we need data on outlays by multiple government agencies, NGOs, and foundations for each disease and year. Although the NIH provides a long time-series of funding at the project level, collecting similar information from funders in other countries is challenging. Fortunately, Policy Cures collects and classifies funding outlays by disease, as described below. We also include data on the burden of disease at the country level, and data on scientific knowledge for each disease. We use data on the composition of Congressional appropriations committees as a source of exogenous variation in US outlays.

\subsection{Funding data}

We focus on infectious and parasitic diseases ${ }^{7}$ because of the availability of high-quality data on funding from all relevant governments and foundations. Policy Cures collects the G-FINDER data using an annual survey. The survey covers public (government) and private (foundation and NGO) funding for 35 neglected diseases, including both infectious and parasitic diseases that predominantly affect people in developing countries. The annual survey defines neglected diseases as those for which treatments are needed in developing countries and for which the commercial market is insufficient to attract R\&D spending by private industry.

Each record in the G-FINDER database includes the disease name, product category, funder name, funder type, home country of the funder, funding amount, year, and recipient information. A key contribution of the annual survey is that it allows a more accurate classification of spending by disease than a survey based on keywords. Furthermore, the G-FINDER database avoids double counting, such as funding that flows from the Gates Foundation to another organization, which then funds research. For more details on the G-FINDER data, see previous studies such as ? and ?.

We aggregate the G-FINDER data to the disease-funder-year level and adjust all outlays to 2013 US dollars. We set the outlay to zero for any disease-country-year and disease-

\footnotetext{
${ }^{7}$ Infectious and parasitic diseases are of interest for many reasons, not only because of the availability of data. First, these diseases are neglected by the private sector, because the disease burden is concentrated in poor countries, where the profits are low (?). The case for government intervention is strong, because the social burden of these diseases is substantial, and government-funded research is unlikely to crowd out private investment. Second, infectious and parasitic diseases tend to cross borders. This suggests that the benefit of curing a disease is not limited to a single country, but rather reaches all countries to which the disease might spread.
} 
funder-year that is missing in the G-FINDER database, so the data are fully rectangular at the disease-country-year level and disease-funder-year level. Thus, we have a sample of funders that ever funded one of the diseases between 2007 and 2014.

\subsection{Disease burden}

We use a standard measure of disease burden from the World Health Organization's (WHO) Global Burden of Disease project. The WHO reports the burden of disease in terms of DALYs lost, an estimate of years of life lost due to premature mortality and years of life lost due to time lived in less than full health. The WHO reports burdens by disease and country for the years 2000 and 2012. We linearly impute values between 2000 and 2012. As a robustness check, we also use country-year-disease mortality data from the Global Health Data Exchange's Global Burden of Disease Study.

We match the disease burden data to the funding data at the disease level. Some diseases in G-FINDER are not included in the disease burden data and vice versa, so our sample consists of 15 diseases.$^{8}$ Neither Ebola nor Zika are in our sample because the burden of disease datasets do not provide separate breakdowns for either one, and Ebola was only introduced in the G-FINDER data in the Policy Cures 2014 survey. ${ }^{9}$

\subsection{State of science}

Scientific knowledge about a disease is another potential determinant of research investment for the disease. Funders might devote more money to diseases with a more advanced state of scientific knowledge, perhaps because such funding is more likely to lead to successful treatments. Furthermore, the existence of many published scientific papers reflects the interest and qualifications of academic researchers, who might submit more and better grant proposals.

We include a control variable for scientific knowledge which we measure as the number to date of publications about a disease indexed in the PubMed database. We include only publications that are coded in PubMed as journal articles, excluding letters, editorials, and reviews. Each article in PubMed includes keywords (or Medical Subject Headings) in its

\footnotetext{
${ }^{8}$ For example, rheumatic fever, included in the G-FINDER data, was not listed as a specific item in the Global Burden of Disease data and thus not included in our sample.

${ }^{9}$ Recent analysis by ? shows that funding for Ebola research increased substantially between 2014 and 2015, when the outbreak peaked. Though accounting for a very small share of total funding from 1997 to 2013, the European contribution for Ebola research exceeded American funding from 2014 to 2015 when American funding declined, consistent with the strategic responses we document in this paper.
} 
listing, which we use to assign to articles to diseases. Specifically, we use the "Entrez" tool from Biopython, an open-source package written in Python, to search the PubMed database for each disease and to extract information on all publications for which the disease is listed among the Medical Subject Headings. Our approach relies on the accuracy of the algorithm used by the National Library of Medicine to assign Medical Subject Headings.

As a robustness check, using data from IMS Health (now known as Quintiles IMS), we include a measure of recent drug innovation as an explanatory variable. We define recent innovation as the number of new treatments introduced for a disease since 1987. Diseases like HIV have experienced significant improvements in available treatments, whereas innovation in other diseases (such as malaria) has been less dramatic.

\subsection{Congressional data}

To construct our instrumental variables (as described in Section ??), we use data on the composition of the House and Senate appropriations committees (?), as well as data on research-intensive universities. In 2015 the Carnegie Classification of Institutions of Higher Education classified 115 universities as classified as having the highest research activity (?). We count the university if it is in the state of the member of Congress, even if it is not in the member's district, because university alumni live throughout the state and support funding for the university (?).

\subsection{Other country-level data}

We also use country-level information on gross domestic product (GDP) per capita, downloaded from the World Development Indicators database. We adjust the amounts for purchasing power parity and inflation (2011 US dollars).

\section{Results}

\subsection{Summary statistics}

The sample includes 15 diseases: 6 infectious and 9 parasitic diseases for which we had data on both funding and disease burden. The data sample includes the period from 2007 to 2014 and 398 funders: 259 government agencies and 139 NGOs. The 41 countries include 6 in Africa, 8 in Asia, 2 in Australia, 17 in Europe, 3 in North America, and 5 in South America. 
For a given disease in a given year, a funder allocated a mean of $\$ 200,000$. Aggregating to a country level generates a mean of $\$ 1.5$ million (Table ??).

Diseases with a greater burden and more scientific knowledge tend to have greater funding outlays (consistent with Hypothesis ??). For example, HIV/AIDS has the greatest global disease burden, number of scientific publications to date, and global outlays (Table ??). The global outlays for HIV are predominately from government agencies (87\% of funding) and the remainder from NGOs and foundations. For a typical disease, government agencies account for two thirds of funding.

Funding for neglected diseases by the US government is much higher than funding by other governments, both in absolute terms (Table ??) and relative to national income (Figure ??) (consistent with Hypotheses ?? and ??). The US government accounted for 59 percent of the total funding outlays for the 15 diseases in our sample, with the majority of that funding coming from the NIH (Table ??). Furthermore, measured as a share of national income, US funding for neglected diseases is at least triple that of any other country except the UK (Figure ??).

Funding outlays by other countries are not necessarily proportional to the number of scientific publications and burden of disease. For example, the government of Brazil provides less medical research funding for HIV/AIDS than for dengue, leishmaniasis, and malaria, each of which has a smaller burden of disease in Brazil than does HIV/AIDS (Table ??). One interpretation of the pattern is that Brazil may spend less on HIV/AIDS because it benefited from the funding for HIV/AIDS provided by the US. Indeed, the US heavily funded HIV/AIDS medical research, which allowed other countries to focus on other diseases of local importance. Hence, research on dengue received more outlays in Latin America and the Caribbean than did HIV/AIDS (consistent with Hypothesis ??).

\subsection{Regression results}

Recall that the dependent variable is the log of disease-funder-year outlays. Many of the independent variables are also in logs, so their coefficients are elasticities. In the tables with the regression results (beginning with Table ??), we include both the instrumental variable results and the ordinary least squares results. We present regression results for government agencies only (Table ??) and for both government agencies and private foundations combined (Table ??). There are 15 diseases, 8 years, and 398 funders, for a total of 47,760 observations. One year is lost due to lagged values when estimating the regressions, so in the regressions the number of observations is 41,790 (with all funders) or 27,195 (with only government 
agencies).

The first-stage of the regression results yields positive, statistically significant coefficients on the average number of research-intensive universities represented by Congressional appropriations committee members (Tables ??-??). The results suggest that a higher number of research-intensive universities represented on a Congressional appropriation committee yields higher research funding. This positive relationship between Congressional representation and outlays is also evident in Figure ??.

The sign on US government outlays differs between the ordinary least squares (OLS) and instrumental variable specifications (Table ??). Whereas the OLS results have a positive coefficient on US outlays, the instrumental variable specification gives the opposite result. The difference in sign suggests that unobserved factors drive R\&D in both the US and other countries and create a spurious positive correlation in the OLS. Sargan test results indicate that the instrumental variables are uncorrelated with the residuals, and therefore are acceptable instruments. When the endogeneity of US outlays is accounted for, a 10 percent increase in US government outlays is associated with a decrease in outlays by funders in other countries in the following year (consistent with Hypothesis ??). The decrease ranges from 2 percent (Table ??) to 3 percent (Table ??).

Disease burden appears to influence outlays, consistent with Hypothesis ??. A 10 percent greater disease burden is associated with 1 percent greater outlays by the US government and by other governments. Likewise, outlays relate to scientific knowledge. A 10 percent greater number of scientific articles to date for a disease in a year is associated with a 10 percent increase in US government outlays. For government funders from other countries, the effect is half as large (Table ??). The coefficient on the HIV/AIDS indicator variable is positive and significant (Table ??). This is not surprising because HIV/AIDS receives more US funding than all other infectious and parasitic diseases combined (Table ??).

The sign on the coefficient for lagged GDP per capita is not statistically significant in most of the regression results. Because we include funder fixed effects, the coefficient on GDP per capita captures within-country variation over time. Normally, we would expect spending to increase when a country's economic performance is strong. The coefficient could plausibly be negative if outlays are intended as economic stimuli, but again, are typically not statistically or economically significant.

Table ??, shows the results when we interact the local disease burden with US outlays. The results suggest that funders with a large local disease burden are highly responsive to changes in US outlays for that disease, while funders with no local disease burden react little 
(the coefficient on US outlays alone was statistically and economically insignificant). In general, diseases with small local burdens receive less funding, so the potential for a negative response is limited.

We also examine the extensive margin; that is, whether other funders start or stop funding a disease in a given year in response to changes in US outlays for the disease in the previous year. The dependent variable for the analysis summarized in Table ??, was an indicator variable for whether outlays are positive. We observe a negative relationship between US outlays and subsequent starting or stopping of outlays by other funders for a given disease, but the effect is small. Countries are unlikely to start or stop funding for a disease entirely based on US medical research funding actions. Hence, the effects of US outlays seem to occur on the intensive margin (Table ??) rather than on the extensive margin (Table ??).

\subsection{Results from robustness checks}

We conduct five robustness checks (Appendix A). First, we include a count of the number of treatments introduced since 1987 to examine how the availability of existing treatments influence funding outlays. The availability of treatments is associated with higher levels of funding (Table ??). Perhaps these diseases receive more funding because there is a record of success in developing treatments for these diseases. Regardless of the reason for the positive relationship between the number of treatments and amount of funding, the results for the response to changes in US outlays are consistent with the results of the main analysis.

Second, rather than using the composition of Congressional appropriations committees as the instrumental variable, we use the NIH budget. We subtract from the budget the funding for the disease in question (although it is a small share of the total, we want to avoid having outlays for that disease on both the left and the right sides of the equation). The rationale for the validity of this instrument is the same as that for the composition of the Congressional appropriations committees; that is, disease funding in the US is correlated with the total NIH budget, but the total NIH budget should not affect the decisions of other funders directly. In this specification, the coefficient on US outlays is -0.2 (Table ??), which is comparable to results of the main analysis.

Third, we drop the scientific knowledge control variable, because our measure (number of scientific publications to date) might be simultaneously determined by funding. With this omission, the US outlays coefficient was slightly smaller but qualitatively similar: -0.26 with the scientific knowledge control variable compared to -0.18 without it (Table ??).

Fourth, we incorporate an alternative measure of disease burden. Recall that DALYs are 
available from only 2000 and 2012, and we linearly interpolate DALY values for the other years. Annual mortality data are available. The results are largely unchanged (Table ??) when using mortality rather than DALYs as a measure of disease burden.

Finally, we replace the 1-year lag for US outlays with a 2-year lag, in case it takes more time for non-US funders to observe a change in US outlays and implement a response. With a longer lag, the coefficient on US outlays was smaller in magnitude than that of the 1-year lag and not statistically significant (Table ??).

\subsection{Discussion}

What is the economic magnitude of the strategic response by non-US funders to American investment in medical research? Based on the US share of outlays (about one half) and the estimated elasticities from the regressions (-0.2 to -0.3$)$, our results suggest that if the US increases outlays by one dollar for a disease, then the net outlay will be around $\$ 0.70$ to $\$ 0.80$.

Regardless of the explanation for the response - i.e. whether free riding, crowding out, or optimal reallocation by non-US funders - this result has implications for estimating the impact of US funding. Demonstrating that basic research has positive, measurable effects is important for sustaining government funding. Indeed, the NIH website emphasizes its impact on health, society, and the scientific community 10 A large literature in economics estimates the effect of NIH funding on the production of scientific papers and development of new drugs. In general, if the response of non-US funders is ignored, then the funding is measured incorrectly. This is likely to bias downward estimates of NIH impact.

\section{Conclusions}

Governments and foundations advance science by funding research and then sharing the results with the public. Funding of medical research may exhibit free riding or crowding out, particularly among the high-income countries that are capable of financing it. In our sample, the US government provides more than half of global government and foundation funding for research on infectious and parasitic diseases (Table ??). Also, US medical research spending as a share of GDP is triple that of all other high-income countries except the UK (Figure ??). In 2003, the Commissioner of the US Food \& Drug Administration noted the disparity

\footnotetext{
${ }^{10}$ For example, see https://www.nih.gov/about-nih/what-we-do/impact-nih-research
} 
in medical research funding between the US and other high-income countries as well as its implications:

"Our governments need to start by sharing the burden of the increasingly complex basic science that goes into the development of new drugs and biologics. In the United States, we've responded to the new opportunities that exist in the lab, by doubling our NIH budget to over $\$ 27$ billion. As a share of GDP, this is about four times as much as European Union countries spend. But on an interconnected planet, all of this spending turns into biomedical knowledge that is transmitted worldwide for the good of public health worldwide. If other developed countries contributed to this worldwide effort in proportion to their GDP, we would build the foundations for better treatments much faster" (?).

We document how governments respond to other funders in supporting medical research. First, we show a negative correlation between outlays for a disease by the US government and outlays by other governments, NGOs, and foundations in the following year, while accounting for the endogeneity of US outlays. We also find that in Latin America and the Caribbean, HIV/AIDS imposed the greatest disease burden, but received less in total funding outlays than diseases like Chagas and dengue. Indeed, the government of Brazil spent less on HIV/AIDS research than on Chagas and dengue research, even though Brazil's disease burden from HIV/AIDS was 100 times greater than the burden from Chagas and dengue (Table ??). A typical model of funding allocation that ignores the role of a dominant funder like the NIH would have difficulty explaining these patterns.

We focus on infectious and parasitic diseases in this paper, in part because of the availability of detailed data. However, our results might hold for other diseases. In 2014, the NIH budget for all diseases was more than 12 times greater than its UK equivalent, the Medical Research Council. ${ }^{11}$ This ratio is similar to that observed for our subset of diseases (Table ??). In future research, it would be interesting to examine whether the results change if we examine a disease that burdens rich and poor alike, such as cancer or diabetes.

We find a negative relationship in outlays across funders, but the magnitude is less than one, meaning that other governments reduce outlays by less than one dollar when the US increases outlays by one dollar. This finding is consistent with our model, which predicts that the relationship will be less than one-to-one when there are differences in budgets across

\footnotetext{
${ }^{11}$ The US NIH budget in fiscal years 2014 and 2015 was approximately $\$ 30$ billion while the UK MRC budget in 2014-15 was less than $£ 1$ billion.
} 
funders. Furthermore, funders may have other objectives that we do not consider explicitly, including a desire to fund research at favored institutions (??) or to show progress fighting a disease. Also, there might be other frictions that mute awareness or action on funding changes.

If we assume that all high-income countries have similar research productivity and assessments of the value of curing diseases, we should expect roughly similar per-capita spending across countries. However, the US government provides more than half of global government and foundation funding for research on the 15 infectious and parasitic diseases in our analysis. Furthermore, US medical research spending as a share of GDP is triple all other high-income countries, other than the UK. This evidence is consistent with free riding. While much of our evidence is consistent with free riding, the regression results are also consistent with optimal reallocation. Indeed, according to a program officer of the Burroughs Wellcome Fund, "We avoid funding areas that the federal government is funding in order to focus on the underserved. This is how many of our philanthropic peers operate. For example, when the NIH developed its translational science programs, we retired ours." Likewise, asked about the objectives of the Gates Foundation, an employee wrote, "the primary driver is perceived neglect and opportunity for impact in a disease area which brings together both health impact and other donor support." ${ }^{12}$ The Congressionally Directed Medical Research Programs Review Process in the US is tasked with identifying and avoiding duplicative research funding, but focuses primarily on avoiding overlap across US government agencies and with NGOs; in fact, a recent evaluation of this process makes no mention of non-US funding (?).

Without a general equilibrium analysis, we cannot determine the extent to which our results indicate free riding or optimal reallocation. Nevertheless, it is useful to be aware of how global resources shift when the US changes its medical research funding outlays.

Documenting government responses to changes in medical research funding outlays is relevant to both research and policy sectors. Scholars should be aware that estimates of the impact of one additional dollar of NIH funding could underestimate the effect, because the net increase in funding for that disease will be smaller.

Policy makers should be aware of how governments adjust funding and consider enhancing international coordination, regardless of whether the negative relationship across funders is socially optimal. The evidence in this paper suggests that governments should increase

\footnotetext{
${ }^{12}$ Sources: email correspondence with a Gates Foundation employee on August 8, 2012 and with a Burroughs Wellcome program officer on December 9, 2016.
} 
efforts to coordinate on medical R\&D funding through organizations such as the World Health Organization as they do in other areas, including military defense and environmental regulation. 
Table 1: Summary Statistics: Diseases

\begin{tabular}{|c|c|c|c|c|c|c|c|c|}
\hline \multirow[b]{2}{*}{ Indication } & \multirow{2}{*}{$\begin{array}{l}\text { Count of } \\
\text { Govt. } \\
\text { Agencies }\end{array}$} & \multirow{2}{*}{$\begin{array}{r}\text { Number of } \\
\text { Publications } \\
\text { to date } \\
(\mathrm{MM}) \\
\end{array}$} & \multicolumn{2}{|c|}{ Global } & \multicolumn{2}{|c|}{ USA Government } & \multicolumn{2}{|c|}{ Brazil Gov. } \\
\hline & & & $\begin{array}{r}\text { Disease } \\
\text { Burden } \\
(000)\end{array}$ & $\begin{array}{r}\text { Mean } \\
\text { Outlay } \\
(\$ M M)\end{array}$ & $\begin{array}{r}\text { Disease } \\
\text { Burden } \\
(000)\end{array}$ & $\begin{array}{r}\text { Mean } \\
\text { Outlay } \\
(\$ M M)\end{array}$ & $\begin{array}{r}\text { Disease } \\
\text { Burden } \\
(000)\end{array}$ & $\begin{array}{r}\text { Mean } \\
\text { Outlay } \\
(\$ M M)\end{array}$ \\
\hline Infectious Disease & & & & & & & & \\
\hline Dengue & 63 & 6 & 1007 & 83 & 0 & 53 & 4 & 7 \\
\hline HIV/AIDS & 97 & 74 & 101632 & 1124 & 494 & 840 & 838 & 0.8 \\
\hline Leprosy & 17 & 11 & 219 & 10 & 0 & 5 & 1 & 1 \\
\hline Meningitis & 29 & 7 & 41693 & 41 & 2 & 8 & 118 & 0.5 \\
\hline Trachoma & 6 & 11 & 433 & 5 & 0 & 4 & 62 & 0 \\
\hline Tuberculosis & 121 & 72 & 60296 & 410 & 32 & 180 & 326 & 1 \\
\hline Parasitic Disease & & & & & & & & \\
\hline Chagas disease & 37 & 8 & 571 & 18 & 0 & 12 & 3 & 1 \\
\hline Hookworm disease & 5 & 1 & 3469 & 9 & 0 & 2 & 15 & 0 \\
\hline Leishmaniasis & 57 & 13 & 4986 & 48 & 0 & 22 & 37 & 2 \\
\hline Lymphatic filariasis & 15 & 9 & 2534 & 13 & 0 & 5 & 17 & 0 \\
\hline Malaria & 121 & 36 & 78236 & 458 & 46 & 174 & 130 & 2 \\
\hline Onchocerciasis & 4 & 2 & 590 & 7 & 0 & 2 & 2 & 0 \\
\hline Schistosomiasis & 19 & 12 & 3137 & 23 & 0 & 15 & 181 & 1 \\
\hline Trichuriasis & 2 & 1 & 696 & 1 & 0 & 0.5 & 0.4 & 0 \\
\hline Trypanosomiasis & 26 & 3 & 3741 & 41 & 1 & 16 & 11 & 0 \\
\hline
\end{tabular}

Note: The disease burden is measured in disability-adjusted life years (DALYs) lost.

Source: Authors' analysis using data from Policy Cures and the World Health Organization. 
Table 2: Summary Statistics: Funders

\begin{tabular}{|c|c|c|c|}
\hline \multirow[t]{2}{*}{ Funder } & \multirow[t]{2}{*}{ Percent } & \multicolumn{2}{|c|}{$\begin{array}{c}\text { Total Outlays } \\
(\$ M M, 2007-2014)\end{array}$} \\
\hline & & Infectious & Parasitic \\
\hline \multicolumn{4}{|l|}{ Aggregated Government } \\
\hline United States & 58.63 & 8752 & 1989 \\
\hline United Kingdom & 4.72 & 891 & 502 \\
\hline France & 2.86 & 557 & 286 \\
\hline India & 1.16 & 110 & 102 \\
\hline Australia & 1.14 & 80 & 130 \\
\hline Germany & 1.06 & 130 & 64 \\
\hline Canada & 0.76 & 137 & 1 \\
\hline Netherlands & 0.67 & 99 & 25 \\
\hline Brazil & 0.57 & 63 & 41 \\
\hline Sweden & 0.48 & 65 & 23 \\
\hline 31 other governments & 0.11 & 16 & 5 \\
\hline \multicolumn{4}{|l|}{ Government Agencies } \\
\hline National Institutes of Health, USA & 50.32 & 7572 & 1645 \\
\hline Agency for International Development, USA & 3.89 & 642 & 70 \\
\hline Department of Defense, USA & 3.46 & 406 & 227 \\
\hline Department for International Development, UK & 2.27 & 296 & 120 \\
\hline Medical Research Council, UK & 2.25 & 216 & 196 \\
\hline Institut Pasteur, France & 1.07 & 102 & 94 \\
\hline National Health and Medical Research Council, Australia & 0.93 & 61 & 110 \\
\hline Inserm - Institute of Infectious Diseases, France & 0.83 & 107 & 45 \\
\hline Council of Medical Research, India & 0.75 & 68 & 69 \\
\hline Centers for Disease Control and Prevention, USA & 0.65 & 91 & 29 \\
\hline 249 other government agencies & 0.03 & 4 & 1 \\
\hline \multicolumn{4}{|l|}{ Non-Governmental Organizations } \\
\hline Bill \& Melinda Gates Foundation, USA & 20.41 & 2257 & 1482 \\
\hline The Wellcome Trust, UK & 3.52 & 273 & 372 \\
\hline UBS Optimus Foundation, Switzerland & 0.06 & 7 & 4 \\
\hline Fundacio La Caixa, Spain & 0.06 & 7 & 4 \\
\hline Starr Foundation, USA & 0.06 & 11 & 0 \\
\hline Global Alliance for Vaccines and Immunizations, Switzerland & 0.05 & 8 & 0 \\
\hline ExxonMobil Foundation, USA & 0.04 & 1 & 7 \\
\hline amfAR, The Foundation for AIDS Research, USA & 0.03 & 6 & 0 \\
\hline Global Fund to Fight AIDS, TB and Malaria, Switzerland & 0.03 & 4 & 2 \\
\hline OPEC Foundation for International Development, Austria & 0.03 & 5 & 0 \\
\hline 129 other non-governmental organizations & 0.003 & 0.3 & 0.2 \\
\hline
\end{tabular}


Table 3: Summary Statistics: Units of Observation

\begin{tabular}{llrr}
\hline $\begin{array}{l}\text { Unit of Observation } \\
\text { (observations) }\end{array}$ & Variable & Mean & $\begin{array}{r}\text { Std } \\
\text { Dev }\end{array}$ \\
\hline Disease, Funder, Year & Annual outlay by a funder $(\$ M M)$ & 0.2 & 3 \\
$(47760)$ & Local disease burden $(000)$ & 166 & 1093 \\
& Local disease burden, deaths $(000)$ & 3 & 28 \\
\hline Country, Year & GDP per capita $(\$)$ & 29764 & 22768 \\
$(328)$ & Annual US outlays (\$MM) & 88 & 211 \\
\hline Disease, Year & Number of publications to date $(\mathrm{MM})$ & 18 & 23 \\
$(120)$ & Disease burden in poor countries $(000)$ & 12862 & 21043 \\
& Disease burden in poor countries, deaths $(000)$ & 233 & 414 \\
& Number of treatments launched since 1987 & 2 & 5 \\
\hline Year & Lag research universities per Congressional & 3.7 & 0.1 \\
$(8)$ & appropriations member & 30 & 617 \\
\hline
\end{tabular}

Source: Authors' analysis using data from Policy Cures, PubMed, the World Bank, and the World Health Organization. 
Table 4: The dependent variable is the log of outlays by a government agency for a disease in a year.

\begin{tabular}{|c|c|c|c|}
\hline & \multirow[b]{2}{*}{ OLS } & \multicolumn{2}{|c|}{ Instrumental Variables } \\
\hline & & First Stage & Second Stage \\
\hline Lag log annual US outlays & $\begin{array}{c}0.095 \\
(0.013)\end{array}$ & & $\begin{array}{l}-0.264 \\
(0.080)\end{array}$ \\
\hline Log local disease burden & $\begin{array}{c}0.038 \\
(0.037)\end{array}$ & $\begin{array}{c}0.110 \\
(0.008)\end{array}$ & $\begin{array}{c}0.076 \\
(0.038)\end{array}$ \\
\hline Log burden in poor countries & $\begin{array}{c}0.116 \\
(0.019)\end{array}$ & $\begin{array}{c}0.155 \\
(0.002)\end{array}$ & $\begin{array}{c}0.171 \\
(0.021)\end{array}$ \\
\hline Infectious except HIV indicator & $\begin{array}{c}0.002 \\
(0.052)\end{array}$ & $\begin{array}{l}-0.560 \\
(0.003)\end{array}$ & $\begin{array}{l}-0.202 \\
(0.068)\end{array}$ \\
\hline HIV indicator & $\begin{array}{l}-0.076 \\
(0.198)\end{array}$ & $\begin{array}{c}1.591 \\
(0.011)\end{array}$ & $\begin{array}{c}0.494 \\
(0.232)\end{array}$ \\
\hline Log number of publications to date & $\begin{array}{c}0.281 \\
(0.037)\end{array}$ & $\begin{array}{l}1.100 \\
(0.004)\end{array}$ & $\begin{array}{c}0.679 \\
(0.097)\end{array}$ \\
\hline Lag log GDP per capita & $\begin{array}{l}-0.549 \\
(0.166)\end{array}$ & $\begin{array}{c}1.017 \\
(0.046)\end{array}$ & $\begin{array}{l}-0.228 \\
(0.155)\end{array}$ \\
\hline Lag research universities per Congressional appropriations member & & $\begin{array}{c}2.561 \\
(0.029)\end{array}$ & \\
\hline Agency fixed effect & Yes & Yes & Yes \\
\hline Observations & 27195 & 27195 & 27195 \\
\hline
\end{tabular}

Standard errors in parentheses and are clustered at the agency level.

Source: Authors' analysis using data from Policy Cures, PubMed, the World Bank, and the World Health Organization. 
Table 5: The dependent variable is the log of outlays by a funder (foundation or government agency) for a disease in a year.

\begin{tabular}{|c|c|c|c|}
\hline & \multirow[b]{2}{*}{ OLS } & \multicolumn{2}{|c|}{ Instrumental Variables } \\
\hline & & First Stage & Second Stage \\
\hline Lag log annual US outlays & $\begin{array}{c}0.072 \\
(0.010)\end{array}$ & & $\begin{array}{l}-0.189 \\
(0.058)\end{array}$ \\
\hline Log local burden & $\begin{array}{c}0.060 \\
(0.031)\end{array}$ & $\begin{array}{c}0.142 \\
(0.008)\end{array}$ & $\begin{array}{c}0.096 \\
(0.032)\end{array}$ \\
\hline Log burden in poor countries & $\begin{array}{c}0.087 \\
(0.015)\end{array}$ & $\begin{array}{c}0.147 \\
(0.002)\end{array}$ & $\begin{array}{c}0.125 \\
(0.016)\end{array}$ \\
\hline Infectious except HIV indicator & $\begin{array}{c}0.008 \\
(0.043)\end{array}$ & $\begin{array}{l}-0.556 \\
(0.003)\end{array}$ & $\begin{array}{l}-0.139 \\
(0.056)\end{array}$ \\
\hline HIV indicator & $\begin{array}{l}-0.055 \\
(0.157)\end{array}$ & $\begin{array}{l}1.503 \\
(0.016)\end{array}$ & $\begin{array}{c}0.335 \\
(0.180)\end{array}$ \\
\hline Log number of publications to date & $\begin{array}{c}0.220 \\
(0.027)\end{array}$ & $\begin{array}{l}1.087 \\
(0.004)\end{array}$ & $\begin{array}{c}0.506 \\
(0.070)\end{array}$ \\
\hline Lag log GDP per capita & $\begin{array}{l}-0.469 \\
(0.145)\end{array}$ & $\begin{array}{l}1.048 \\
(0.046)\end{array}$ & $\begin{array}{l}-0.257 \\
(0.134)\end{array}$ \\
\hline Lag research universities per Congressional appropriations member & & $\begin{array}{c}2.612 \\
(0.022)\end{array}$ & \\
\hline Funder fixed effect & Yes & Yes & Yes \\
\hline Observations & 41790 & 41790 & 41790 \\
\hline
\end{tabular}

Standard errors in parentheses and are clustered at the agency level.

Source: Authors' analysis using data from Policy Cures, PubMed, the World Bank, and the World Health Organization. 
Table 6: The dependent variable is the log of outlays by a government agency for a disease in a year. This specification includes the interaction term between US outlay and local disease burden.

\begin{tabular}{|c|c|c|c|c|}
\hline \multirow{3}{*}{ Lag log annual US outlays } & \multirow{3}{*}{$\begin{array}{c}\text { OLS } \\
0.087 \\
(0.017)\end{array}$} & \multicolumn{3}{|c|}{ Instrumental Variables } \\
\hline & & First Stage 1 & First Stage 2 & Second Stage \\
\hline & & & & $\begin{array}{c}0.055 \\
(0.057)\end{array}$ \\
\hline Log local disease burden & $\begin{array}{l}-0.132 \\
(0.245)\end{array}$ & $\begin{array}{l}1.788 \\
(0.101)\end{array}$ & $\begin{array}{l}14.695 \\
(0.170)\end{array}$ & $\begin{array}{c}6.325 \\
(1.674)\end{array}$ \\
\hline Log local disease burden $\mathrm{x}$ Lag log annual US outlays & $\begin{array}{c}0.010 \\
(0.015)\end{array}$ & & & $\begin{array}{l}-0.351 \\
(0.094)\end{array}$ \\
\hline Log burden in poor countries & $\begin{array}{c}0.115 \\
(0.019)\end{array}$ & $\begin{array}{c}0.154 \\
(0.002)\end{array}$ & $\begin{array}{c}0.191 \\
(0.032)\end{array}$ & $\begin{array}{c}0.188 \\
(0.025)\end{array}$ \\
\hline Infectious except HIV indicator & $\begin{array}{c}0.007 \\
(0.053)\end{array}$ & $\begin{array}{l}-0.562 \\
(0.003)\end{array}$ & $\begin{array}{l}-0.947 \\
(0.075)\end{array}$ & $\begin{array}{l}-0.357 \\
(0.096)\end{array}$ \\
\hline HIV indicator & $\begin{array}{l}-0.144 \\
(0.254)\end{array}$ & $\begin{array}{c}1.589 \\
(0.011)\end{array}$ & $\begin{array}{c}8.377 \\
(0.425)\end{array}$ & $\begin{array}{c}2.928 \\
(0.783)\end{array}$ \\
\hline Log number of publications to date & $\begin{array}{c}0.277 \\
(0.037)\end{array}$ & $\begin{array}{l}1.099 \\
(0.004)\end{array}$ & $\begin{array}{l}1.189 \\
(0.118)\end{array}$ & $\begin{array}{c}0.745 \\
(0.110)\end{array}$ \\
\hline Lag log GDP per capita & $\begin{array}{l}-0.564 \\
(0.169)\end{array}$ & $\begin{array}{c}1.111 \\
(0.047)\end{array}$ & $\begin{array}{c}2.206 \\
(0.155)\end{array}$ & $\begin{array}{c}0.285 \\
(0.229)\end{array}$ \\
\hline Lag research universities per Congressional appropriations member & & $\begin{array}{c}3.126 \\
(0.034)\end{array}$ & $\begin{array}{c}1.252 \\
(0.099)\end{array}$ & \\
\hline $\begin{array}{l}\text { Log local burden x Lag research universities per } \\
\text { Congressional appropriations member }\end{array}$ & & $\begin{array}{l}-0.450 \\
(0.025)\end{array}$ & $\begin{array}{c}0.856 \\
(0.040)\end{array}$ & \\
\hline Agency fixed effect & Yes & Yes & Yes & Yes \\
\hline Observations & 27195 & 27195 & 27195 & 27195 \\
\hline
\end{tabular}

Standard errors are in parentheses and are clustered at the agency level.

Source: Authors' analysis using data from Policy Cures, PubMed, the World Bank, and the World Health Organization. 
Table 7: The dependent variable is an indicator variable for whether funding by a government agency is positive (rather than a measure of the magnitude of the funding).

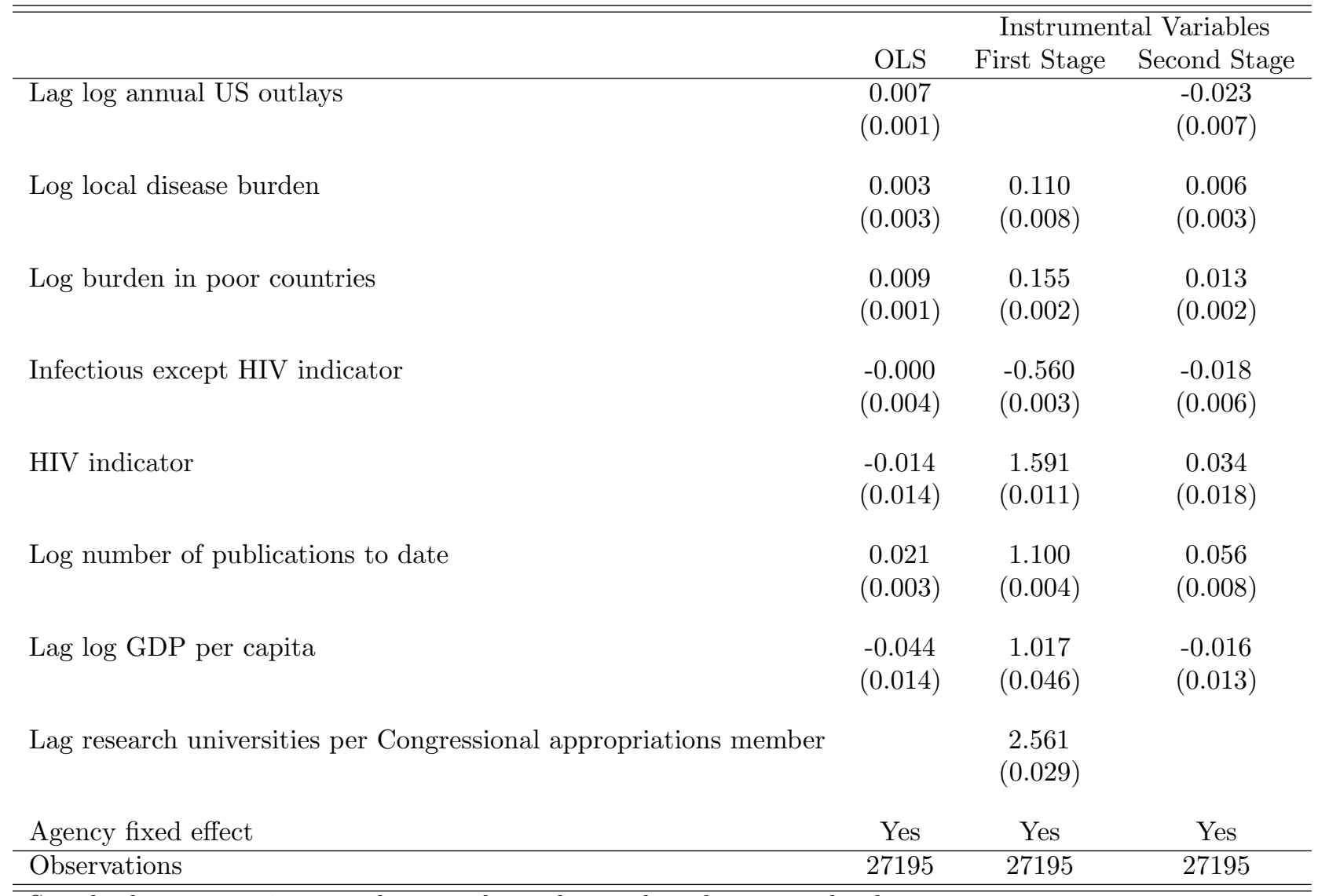

Standard errors are in parentheses and are clustered at the agency level.

Source: Authors' analysis using data from Policy Cures, PubMed, the World Bank, and the World Health Organization. 
Figure 1: Percentage of national income for medical research on 15 infectious and parasitic diseases.

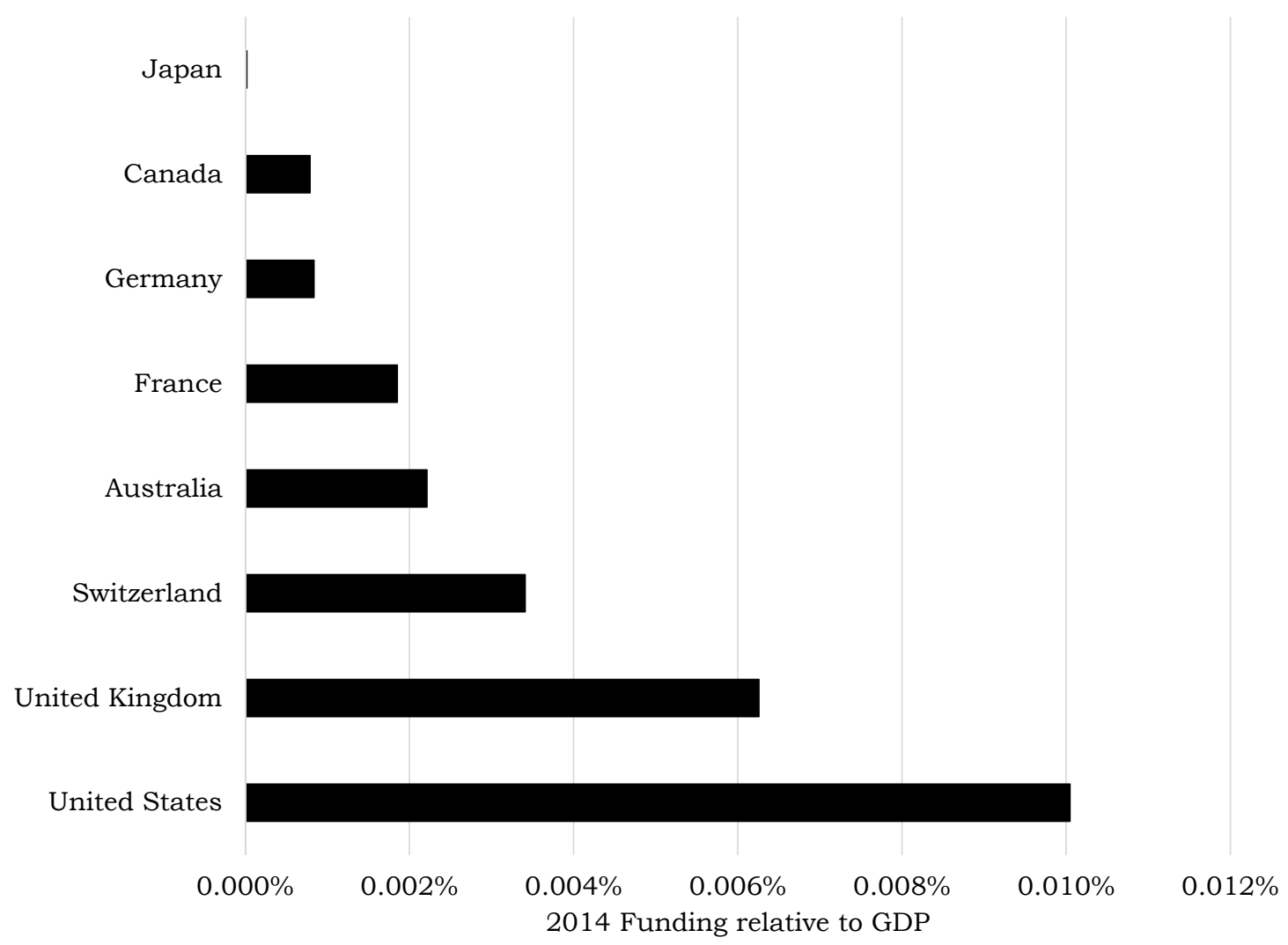

Source: Authors' analysis using data from Policy Cures and the World Bank. 
Figure 2: The magnitude of US outlays appears to depend in part on representation of research-intensive universities on US Congressional appropriations committees.

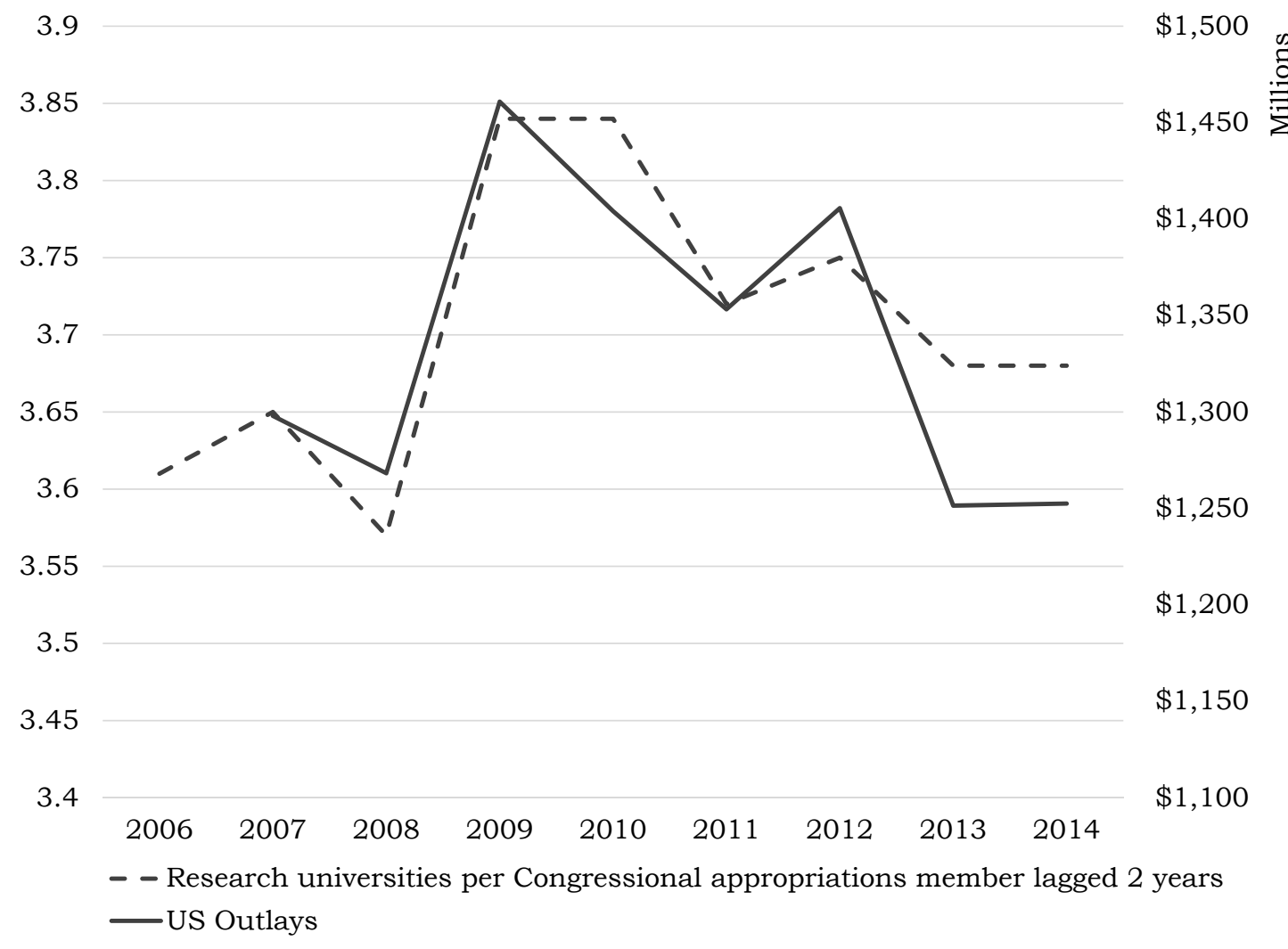

Source: Authors' analysis using US Congressional data, Carnegie university classifications, and Policy Cures data. 


\section{A Robustness Checks}

Table 8: The dependent variable is the log of outlays by a government agency for a disease in a year. This specification includes a new variable: the number of existing treatments.

\begin{tabular}{|c|c|c|c|}
\hline & \multirow[b]{2}{*}{ OLS } & \multicolumn{2}{|c|}{ Instrumental Variables } \\
\hline & & First Stage & Second Stage \\
\hline Lag log annual US outlays & $\begin{array}{c}0.089 \\
(0.012)\end{array}$ & & $\begin{array}{l}-0.369 \\
(0.142)\end{array}$ \\
\hline Log local disease burden & $\begin{array}{c}0.013 \\
(0.039)\end{array}$ & $\begin{array}{c}0.081 \\
(0.007)\end{array}$ & $\begin{array}{c}0.050 \\
(0.040)\end{array}$ \\
\hline Log burden in poor countries & $\begin{array}{c}0.111 \\
(0.019)\end{array}$ & $\begin{array}{c}0.147 \\
(0.001)\end{array}$ & $\begin{array}{c}0.177 \\
(0.029)\end{array}$ \\
\hline Infectious except HIV indicator & $\begin{array}{c}0.125 \\
(0.048)\end{array}$ & $\begin{array}{l}-0.417 \\
(0.003)\end{array}$ & $\begin{array}{l}-0.071 \\
(0.074)\end{array}$ \\
\hline HIV indicator & $\begin{array}{l}-1.268 \\
(0.358)\end{array}$ & $\begin{array}{c}0.227 \\
(0.009)\end{array}$ & $\begin{array}{l}-1.162 \\
(0.357)\end{array}$ \\
\hline Log number of publications to date & $\begin{array}{c}0.209 \\
(0.033)\end{array}$ & $\begin{array}{c}1.012 \\
(0.003)\end{array}$ & $\begin{array}{c}0.678 \\
(0.146)\end{array}$ \\
\hline Lag log GDP per capita & $\begin{array}{l}-0.571 \\
(0.166)\end{array}$ & $\begin{array}{c}0.986 \\
(0.045)\end{array}$ & $\begin{array}{l}-0.175 \\
(0.210)\end{array}$ \\
\hline Number of treatments launched since 1987 & $\begin{array}{c}0.085 \\
(0.021)\end{array}$ & $\begin{array}{c}0.128 \\
(0.001)\end{array}$ & $\begin{array}{c}0.108 \\
(0.025)\end{array}$ \\
\hline Lag research universities per Congressional appropriations member & & $\begin{array}{c}2.568 \\
(0.028)\end{array}$ & \\
\hline Agency fixed effect & Yes & Yes & Yes \\
\hline Observations & 27195 & 27195 & 27195 \\
\hline
\end{tabular}

Standard errors in parentheses and are clustered at the agency level.

Source: Authors' analysis using data from Policy Cures, PubMed, the World Bank, and the World Health Organization. 
Table 9: The dependent variable is the log of outlays by a government agency for a disease in a year. This specification includes a different instrumental variable: the NIH budget (net of funding for the disease in question).

\begin{tabular}{lccc}
\hline \hline & & \multicolumn{2}{c}{ Instrumental Variables } \\
& OLS & First Stage & Second Stage \\
\hline Lag log annual US outlays & 0.095 & & -0.179 \\
& $(0.013)$ & & $(0.064)$ \\
Log local disease burden & 0.038 & 0.110 & 0.067 \\
& $(0.037)$ & $(0.008)$ & $(0.038)$ \\
Log burden in poor countries & 0.116 & 0.155 & 0.158 \\
& $(0.019)$ & $(0.001)$ & $(0.021)$ \\
Infectious except HIV indicator & 0.002 & -0.559 & -0.153 \\
& $(0.052)$ & $(0.003)$ & $(0.062)$ \\
HIV indicator & -0.076 & 1.590 & 0.358 \\
& $(0.198)$ & $(0.011)$ & $(0.222)$ \\
Log number of publications to date & 0.281 & 1.098 & 0.584 \\
& $(0.037)$ & $(0.004)$ & $(0.081)$ \\
Lag log GDP per capita & -0.549 & 0.530 & -0.304 \\
& $(0.166)$ & $(0.031)$ & $(0.167)$ \\
Lag log NIH budget & & 12.666 & \\
Agency fixed effect & & $(0.085)$ & \\
\hline Observations & Yes & Yes & Yes \\
\hline
\end{tabular}

Standard errors are in parentheses and are clustered at the agency level.

Source: Authors' analysis using data from Policy Cures, PubMed, the World Bank, and the World Health Organization. 
Table 10: The dependent variable is the log of outlays by a government agency for a disease in a year. This specification does not include the number of scientific publications as a control variable.

\begin{tabular}{lccc}
\hline \hline & \multicolumn{3}{c}{ Instrumental Variables } \\
& OLS & First Stage & Second Stage \\
\hline Lag log annual US outlays & 0.149 & & -0.182 \\
& $(0.017)$ & & $(0.070)$ \\
Log local burden & 0.076 & 0.333 & 0.187 \\
& $(0.037)$ & $(0.028)$ & $(0.044)$ \\
Log burden in poor countries & 0.153 & 0.378 & 0.277 \\
& $(0.021)$ & $(0.006)$ & $(0.032)$ \\
Infectious except HIV indicator & 0.212 & 0.332 & 0.321 \\
& $(0.053)$ & $(0.011)$ & $(0.058)$ \\
HIV indicator & -0.057 & 2.118 & 0.644 \\
& $(0.197)$ & $(0.048)$ & $(0.241)$ \\
Lag log GDP per capita & -0.504 & 1.504 & -0.051 \\
& $(0.166)$ & $(0.061)$ & $(0.159)$ \\
Lag research universities per Congressional appropriations member & & 2.955 & \\
Agency fixed effect & & $(0.043)$ & \\
\hline Observations & & Yes & Yes \\
\hline \hline
\end{tabular}

Standard errors are in parentheses and are clustered at the agency level.

Source: Authors' analysis using data from Policy Cures, PubMed, the World Bank, and the World Health Organization. 
Table 11: The dependent variable is the log of outlays by a government agency for a disease in a year. This specification measures disease burden by deaths instead of DALYs.

\begin{tabular}{|c|c|c|c|}
\hline & \multirow[b]{2}{*}{ OLS } & \multicolumn{2}{|c|}{ Instrumental Variables } \\
\hline & & First Stage & Second Stage \\
\hline Lag log annual US outlays & $\begin{array}{c}0.049 \\
(0.009)\end{array}$ & & $\begin{array}{l}-0.237 \\
(0.074)\end{array}$ \\
\hline Log local disease burden, deaths & $\begin{array}{c}0.095 \\
(0.036)\end{array}$ & $\begin{array}{l}-0.067 \\
(0.005)\end{array}$ & $\begin{array}{c}0.076 \\
(0.036)\end{array}$ \\
\hline Log burden in poor countries, deaths & $\begin{array}{c}0.036 \\
(0.015)\end{array}$ & $\begin{array}{c}0.248 \\
(0.001)\end{array}$ & $\begin{array}{c}0.106 \\
(0.022)\end{array}$ \\
\hline Infectious except HIV indicator & $\begin{array}{l}-0.240 \\
(0.076)\end{array}$ & $\begin{array}{l}-0.447 \\
(0.008)\end{array}$ & $\begin{array}{l}-0.370 \\
(0.083)\end{array}$ \\
\hline HIV indicator & $\begin{array}{c}0.060 \\
(0.220)\end{array}$ & $\begin{array}{l}1.916 \\
(0.012)\end{array}$ & $\begin{array}{c}0.604 \\
(0.250)\end{array}$ \\
\hline Log number of publications to date & $\begin{array}{c}0.278 \\
(0.036)\end{array}$ & $\begin{array}{c}0.606 \\
(0.001)\end{array}$ & $\begin{array}{c}0.454 \\
(0.056)\end{array}$ \\
\hline Lag log GDP per capita & $\begin{array}{l}-0.483 \\
(0.163)\end{array}$ & $\begin{array}{c}1.262 \\
(0.052)\end{array}$ & $\begin{array}{l}-0.160 \\
(0.156)\end{array}$ \\
\hline Lag research universities per Congressional appropriations member & & $\begin{array}{c}2.749 \\
(0.035)\end{array}$ & \\
\hline Agency fixed effect & Yes & Yes & Yes \\
\hline Observations & 27195 & 27195 & 27195 \\
\hline
\end{tabular}

Standard errors are in parentheses and are clustered at the agency level.

Source: Authors' analysis using data from Policy Cures, PubMed, the World Bank, and the World Health Organization. 
Table 12: The dependent variable is the log of outlays by a government agency for a disease in a year. The specification uses 2-year lagged, rather than 1-year lagged, outlays from the US government.

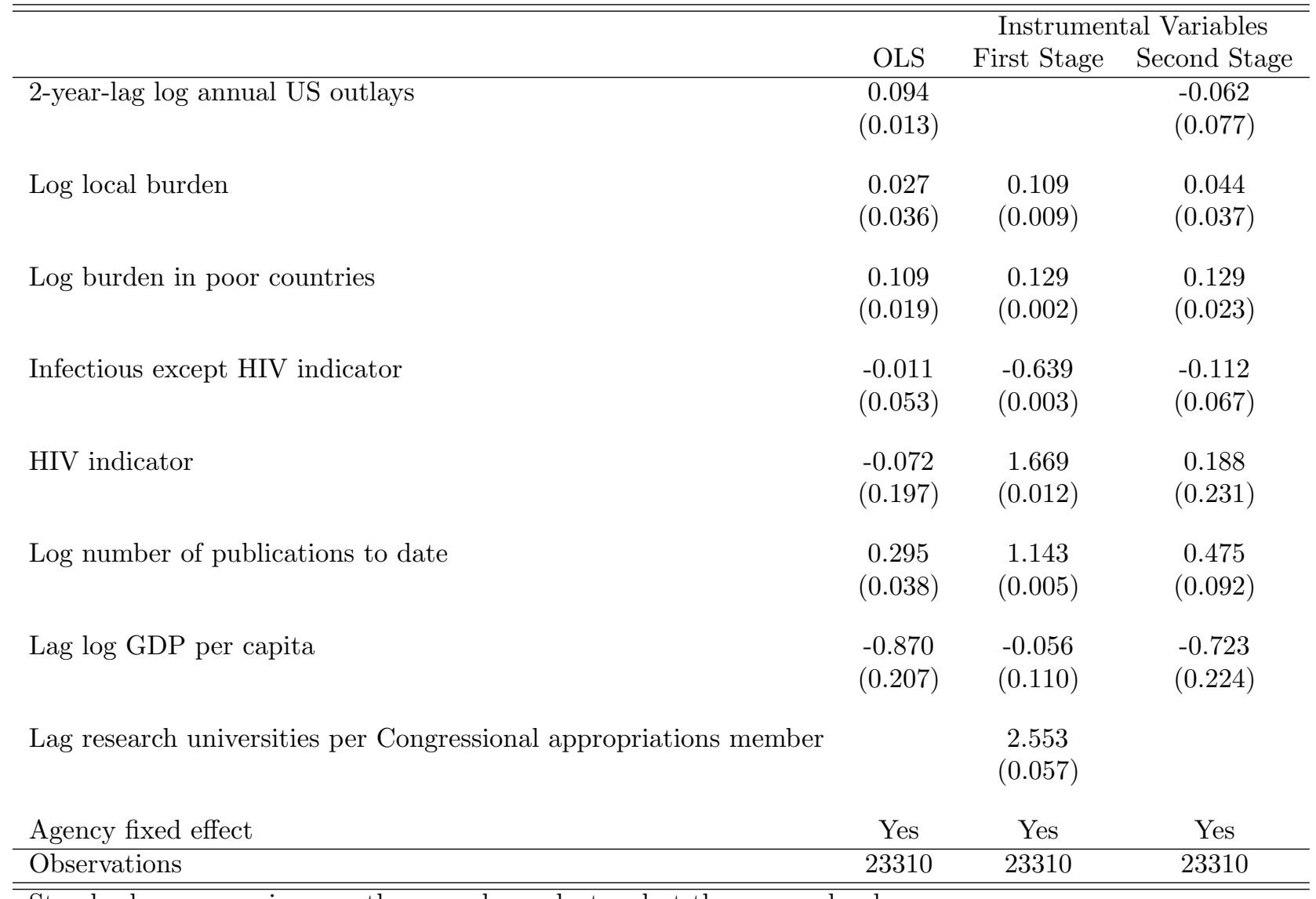

Standard errors are in parentheses and are clustered at the agency level.

Source: Authors' analysis using data from Policy Cures, PubMed, the World Bank, and the World Health Organization. 


\section{A Robustness Checks}

Table 13: The dependent variable is the log of outlays by a government agency for a disease in a year. This specification includes a new variable: the number of existing treatments.

\begin{tabular}{|c|c|c|c|}
\hline & \multirow[b]{2}{*}{ OLS } & \multicolumn{2}{|c|}{ Instrumental Variables } \\
\hline & & First Stage & Second Stage \\
\hline Lag log annual US outlays & $\begin{array}{c}0.089 \\
(0.012)\end{array}$ & & $\begin{array}{l}-0.369 \\
(0.142)\end{array}$ \\
\hline Log local disease burden & $\begin{array}{c}0.013 \\
(0.039)\end{array}$ & $\begin{array}{c}0.081 \\
(0.007)\end{array}$ & $\begin{array}{c}0.050 \\
(0.040)\end{array}$ \\
\hline Log burden in poor countries & $\begin{array}{c}0.111 \\
(0.019)\end{array}$ & $\begin{array}{c}0.147 \\
(0.001)\end{array}$ & $\begin{array}{c}0.177 \\
(0.029)\end{array}$ \\
\hline Infectious except HIV indicator & $\begin{array}{c}0.125 \\
(0.048)\end{array}$ & $\begin{array}{l}-0.417 \\
(0.003)\end{array}$ & $\begin{array}{l}-0.071 \\
(0.074)\end{array}$ \\
\hline HIV indicator & $\begin{array}{l}-1.268 \\
(0.358)\end{array}$ & $\begin{array}{c}0.227 \\
(0.009)\end{array}$ & $\begin{array}{l}-1.162 \\
(0.357)\end{array}$ \\
\hline Log number of publications to date & $\begin{array}{c}0.209 \\
(0.033)\end{array}$ & $\begin{array}{c}1.012 \\
(0.003)\end{array}$ & $\begin{array}{c}0.678 \\
(0.146)\end{array}$ \\
\hline Lag log GDP per capita & $\begin{array}{l}-0.571 \\
(0.166)\end{array}$ & $\begin{array}{c}0.986 \\
(0.045)\end{array}$ & $\begin{array}{l}-0.175 \\
(0.210)\end{array}$ \\
\hline Number of treatments launched since 1987 & $\begin{array}{c}0.085 \\
(0.021)\end{array}$ & $\begin{array}{c}0.128 \\
(0.001)\end{array}$ & $\begin{array}{c}0.108 \\
(0.025)\end{array}$ \\
\hline Lag research universities per Congressional appropriations member & & $\begin{array}{c}2.568 \\
(0.028)\end{array}$ & \\
\hline Agency fixed effect & Yes & Yes & Yes \\
\hline Observations & 27195 & 27195 & 27195 \\
\hline
\end{tabular}

Standard errors in parentheses and are clustered at the agency level.

Source: Authors' analysis using data from Policy Cures, PubMed, the World Bank, and the World Health Organization. 
Table 14: The dependent variable is the log of outlays by a government agency for a disease in a year. This specification includes a different instrumental variable: the NIH budget (net of funding for the disease in question).

\begin{tabular}{lccc}
\hline \hline & & \multicolumn{2}{c}{ Instrumental Variables } \\
& OLS & First Stage & Second Stage \\
\hline Lag log annual US outlays & 0.095 & & -0.179 \\
& $(0.013)$ & & $(0.064)$ \\
Log local disease burden & 0.038 & 0.110 & 0.067 \\
& $(0.037)$ & $(0.008)$ & $(0.038)$ \\
Log burden in poor countries & 0.116 & 0.155 & 0.158 \\
& $(0.019)$ & $(0.001)$ & $(0.021)$ \\
Infectious except HIV indicator & 0.002 & -0.559 & -0.153 \\
& $(0.052)$ & $(0.003)$ & $(0.062)$ \\
HIV indicator & -0.076 & 1.590 & 0.358 \\
& $(0.198)$ & $(0.011)$ & $(0.222)$ \\
Log number of publications to date & 0.281 & 1.098 & 0.584 \\
& $(0.037)$ & $(0.004)$ & $(0.081)$ \\
Lag log GDP per capita & -0.549 & 0.530 & -0.304 \\
& $(0.166)$ & $(0.031)$ & $(0.167)$ \\
Lag log NIH budget & & 12.666 & \\
Agency fixed effect & & $(0.085)$ & \\
\hline Observations & Yes & Yes & Yes \\
\hline
\end{tabular}

Standard errors are in parentheses and are clustered at the agency level.

Source: Authors' analysis using data from Policy Cures, PubMed, the World Bank, and the World Health Organization. 
Table 15: The dependent variable is the log of outlays by a government agency for a disease in a year. This specification does not include the number of scientific publications as a control variable.

\begin{tabular}{lccc}
\hline \hline & \multicolumn{3}{c}{ Instrumental Variables } \\
& OLS & First Stage & Second Stage \\
\hline Lag log annual US outlays & 0.149 & & -0.182 \\
& $(0.017)$ & & $(0.070)$ \\
Log local burden & 0.076 & 0.333 & 0.187 \\
& $(0.037)$ & $(0.028)$ & $(0.044)$ \\
Log burden in poor countries & 0.153 & 0.378 & 0.277 \\
& $(0.021)$ & $(0.006)$ & $(0.032)$ \\
Infectious except HIV indicator & 0.212 & 0.332 & 0.321 \\
& $(0.053)$ & $(0.011)$ & $(0.058)$ \\
HIV indicator & -0.057 & 2.118 & 0.644 \\
& $(0.197)$ & $(0.048)$ & $(0.241)$ \\
Lag log GDP per capita & -0.504 & 1.504 & -0.051 \\
& $(0.166)$ & $(0.061)$ & $(0.159)$ \\
Lag research universities per Congressional appropriations member & & 2.955 & \\
Agency fixed effect & & $(0.043)$ & \\
\hline Observations & & Yes & Yes \\
\hline \hline
\end{tabular}

Standard errors are in parentheses and are clustered at the agency level.

Source: Authors' analysis using data from Policy Cures, PubMed, the World Bank, and the World Health Organization. 
Table 16: The dependent variable is the log of outlays by a government agency for a disease in a year. This specification measures disease burden by deaths instead of DALYs.

\begin{tabular}{|c|c|c|c|}
\hline & \multirow[b]{2}{*}{ OLS } & \multicolumn{2}{|c|}{ Instrumental Variables } \\
\hline & & First Stage & Second Stage \\
\hline Lag log annual US outlays & $\begin{array}{c}0.049 \\
(0.009)\end{array}$ & & $\begin{array}{l}-0.237 \\
(0.074)\end{array}$ \\
\hline Log local disease burden, deaths & $\begin{array}{c}0.095 \\
(0.036)\end{array}$ & $\begin{array}{l}-0.067 \\
(0.005)\end{array}$ & $\begin{array}{c}0.076 \\
(0.036)\end{array}$ \\
\hline Log burden in poor countries, deaths & $\begin{array}{c}0.036 \\
(0.015)\end{array}$ & $\begin{array}{c}0.248 \\
(0.001)\end{array}$ & $\begin{array}{c}0.106 \\
(0.022)\end{array}$ \\
\hline Infectious except HIV indicator & $\begin{array}{l}-0.240 \\
(0.076)\end{array}$ & $\begin{array}{l}-0.447 \\
(0.008)\end{array}$ & $\begin{array}{l}-0.370 \\
(0.083)\end{array}$ \\
\hline HIV indicator & $\begin{array}{c}0.060 \\
(0.220)\end{array}$ & $\begin{array}{l}1.916 \\
(0.012)\end{array}$ & $\begin{array}{c}0.604 \\
(0.250)\end{array}$ \\
\hline Log number of publications to date & $\begin{array}{c}0.278 \\
(0.036)\end{array}$ & $\begin{array}{c}0.606 \\
(0.001)\end{array}$ & $\begin{array}{c}0.454 \\
(0.056)\end{array}$ \\
\hline Lag log GDP per capita & $\begin{array}{l}-0.483 \\
(0.163)\end{array}$ & $\begin{array}{c}1.262 \\
(0.052)\end{array}$ & $\begin{array}{l}-0.160 \\
(0.156)\end{array}$ \\
\hline Lag research universities per Congressional appropriations member & & $\begin{array}{c}2.749 \\
(0.035)\end{array}$ & \\
\hline Agency fixed effect & Yes & Yes & Yes \\
\hline Observations & 27195 & 27195 & 27195 \\
\hline
\end{tabular}

Standard errors are in parentheses and are clustered at the agency level.

Source: Authors' analysis using data from Policy Cures, PubMed, the World Bank, and the World Health Organization. 
Table 17: The dependent variable is the log of outlays by a government agency for a disease in a year. The specification uses 2-year lagged, rather than 1-year lagged, outlays from the US government.

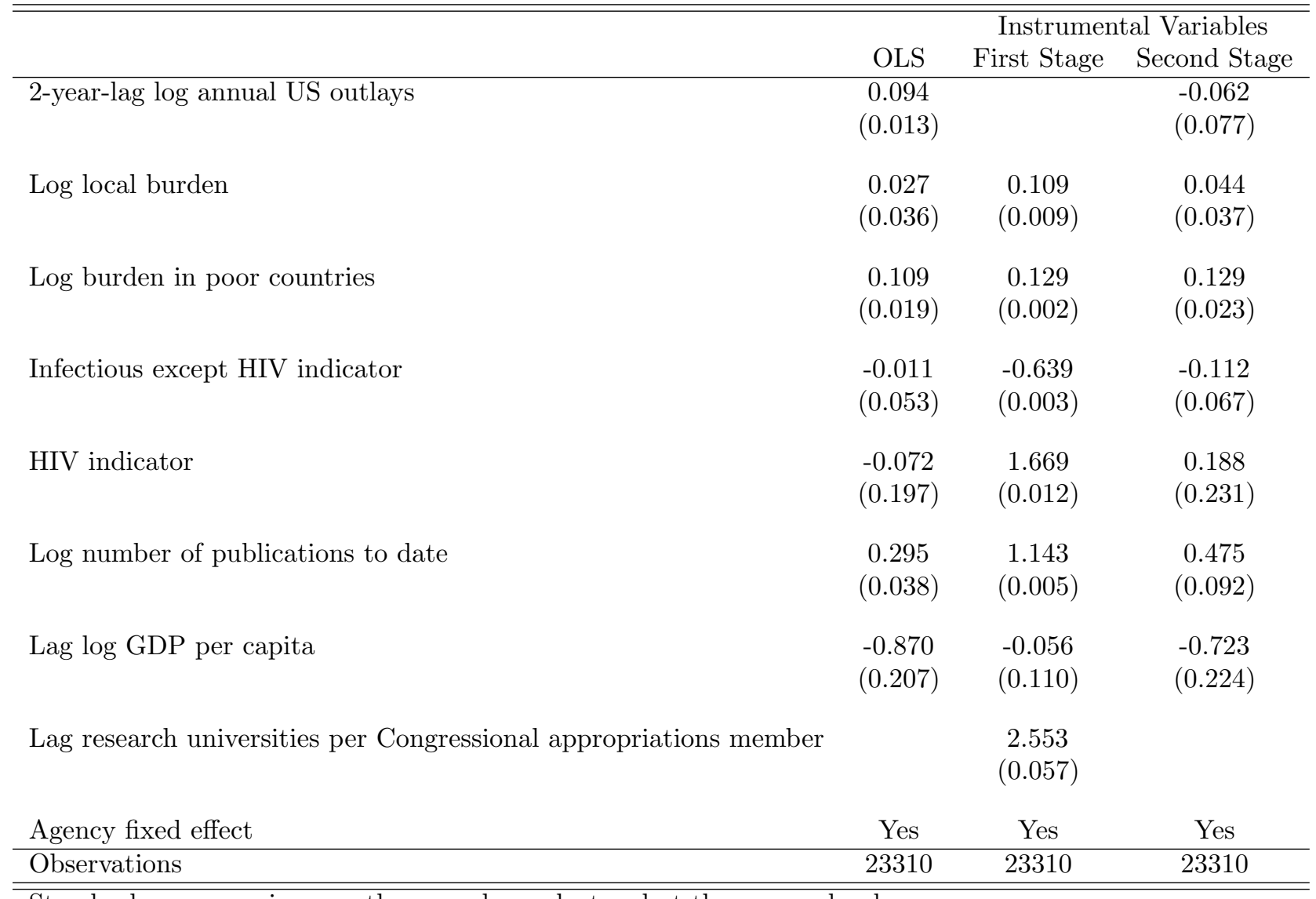

Standard errors are in parentheses and are clustered at the agency level.

Source: Authors' analysis using data from Policy Cures, PubMed, the World Bank, and the World Health Organization. 


\section{B Theory}

Consider a simple version of the model with two funders, $i$ and $j$, two diseases, $a$ and $b$, and an outside option $o^{f}$, which is specific to a funder. Assume two stages. In stage one, funder $i$ distributes funding across diseases based on the burden of disease that can be alleviated $B$ and scientific knowledge $S$, while ignoring outlays from the fringe funder $j$. In stage two, funder $j$ distributes funding according to its local disease burden, scientific knowledge, and the funding from funder $i$.

The dominant funder chooses outlays without regard to outlays by the fringe funder. The dominant funder model seems appropriate in our context for two reasons. First, the US government accounts for the majority of global funding for 15 infectious and parasitic diseases in our analysis, while the median funder in our sample accounts for less than 1 percent of overall funding (Table ??). The combination of NIH and Gates Foundation accounts for 70 percent of funding. Second, we could find no evidence that the NIH or other government agencies factor in the behavior of non-US funders. Consistent with our model, $\mathrm{NIH}$ leaders quoted in the text described funding priorities based on disease burden and scientific knowledge without mention of other funders (?). In contrast, other funders often mention that they are filling perceived gaps. Recall the quote from a program officer of the Burroughs Wellcome Fund who described avoiding funding of areas that the US government funds.

Following the innovation economics literature, we assume the production function of treatment, $g\left(\sum_{f} x_{d}^{f}, S_{d}\right)=S_{d}\left(1-e^{-\sum_{f} x_{d}^{f}}\right)(? ?)$. Also, we assume $h\left(o^{f}\right)=1-e^{-o^{f}}$, but our results are robust to other functional forms of $h\left(o^{f}\right)$. Under these assumptions, we can rewrite the objective function of funder $i$ (Equation ??) as

$$
\begin{gathered}
\max _{x_{d}^{i}} B_{a} S_{a}\left(1-e^{-x_{a}^{i}}\right)+B_{b} S_{b}\left(1-e^{-x_{b}^{i}}\right)+\left(1-e^{-o^{i}}\right) \\
\text { s.t. }: x_{a}^{i}+x_{b}^{i}+o^{i}=Y^{i}
\end{gathered}
$$

The optimal funding distribution for funder $i$ is summarized by three equations:

$$
\begin{aligned}
& x_{a}^{i *}=\frac{Y^{i}+2 \log \left(B_{a} S_{a}\right)-\log \left(B_{b} S_{b}\right)}{3} \\
& x_{b}^{i *}=\frac{Y^{i}-\log \left(B_{a} S_{a}\right)+2 \log \left(B_{b} S_{b}\right)}{3}
\end{aligned}
$$




$$
o^{i *}=\frac{Y^{i}-\log \left(B_{a} S_{a}\right)-\log \left(B_{b} S_{b}\right)}{3}
$$

It is straightforward to show that

$$
\begin{aligned}
& \frac{\partial x_{a}^{i *}}{\partial B_{a}}=\frac{2}{3 B_{a}}>0 \\
& \frac{\partial x_{a}^{i *}}{\partial S_{a}}=\frac{2}{3 S_{a}}>0,
\end{aligned}
$$

which suggests that the dominant funder $i$ provides greater outlays for diseases with higher burdens and/or diseases with higher scientific knowledge.

Now we solve for the optimal outlays by the fringe funder $j$. The objective function for the fringe funder $j$, when funder $j$ considers local disease burden only, is:

$$
\begin{gathered}
\max _{x_{d}^{j}} B_{a}^{j} S_{a}\left(1-e^{-x_{a}^{i *}-x_{a}^{j}}\right)+B_{b}^{j} S_{b}\left(1-e^{-x_{b}^{i *}-x_{b}^{j}}\right)+\left(1-e^{-o^{i}}\right) \\
\text { s.t. }: x_{a}^{j}+x_{b}^{j}+o^{j}=Y^{j},
\end{gathered}
$$

The optimal outlays by funder $j$, given the funding from funder $i$, are:

$$
\begin{aligned}
x_{a}^{j *} & =\frac{Y^{j}-2 x_{a}^{i *}+x_{b}^{j *}+2 \log \left(B_{a}^{j} S_{a}\right)-\log \left(B_{b}^{j} S_{b}\right)}{3} \\
x_{b}^{j *} & =\frac{Y^{j}-2 x_{b}^{i *}+x_{a}^{i *}-\log \left(B_{a}^{j} S_{a}\right)+2 \log \left(B_{b}^{j} S_{b}\right)}{3} \\
o^{j *} & =\frac{Y^{j}+x_{b}^{i *}+x_{a}^{i *}+\log \left(B_{a}^{j} S_{a}\right)+\log \left(B_{b}^{j} S_{b}\right)}{3}
\end{aligned}
$$

Now we consider how the fringe funder $j$ responds to changes in outlays by the dominant funder $i$.

$$
\frac{\partial x_{a}^{j *}}{\partial x_{a}^{i *}}=\frac{\partial x_{b}^{j *}}{\partial x_{b}^{i *}}=-\frac{2}{3}<0
$$

and

$$
\frac{\partial x_{a}^{j *}}{\partial x_{b}^{i *}}=\frac{\partial x_{b}^{j *}}{\partial x_{a}^{i *}}=\frac{1}{3}>0
$$

Thus, greater outlays for a disease by the dominant funder will reduce outlays for the disease by the fringe funder (Hypothesis ??) and increase outlays for a different disease by 
the fringe funder (Hypothesis ??).

In addition, we have

$$
\frac{\partial x_{a}^{j *}+x_{b}^{j *}}{\partial x_{b}^{i *}}=\frac{\partial x_{a}^{j *}+x_{b}^{j *}}{\partial x_{a}^{i *}}=-\frac{1}{3}<0 .
$$

In other words, increased outlays by the dominant funder would induce the fringe funder to invest less in global diseases overall (Hypothesis ??).

Finally, we briefly discuss how exogenous shocks to disease burden, scientific knowledge, and the budget of funders affect the funding decision of funder $f$, and explain the importance of using instrumental variables for identification with a simple example. We start with disease burden and scientific foundation. As in equation ??, we have

$$
\begin{aligned}
& \frac{\partial x_{a}^{j *}}{\partial B_{a}^{j}}=\frac{2}{3 B_{a}^{j}}-\frac{5}{9 B_{a}}>0 \\
& \frac{\partial x_{a}^{j *}}{\partial S_{a}^{j}}=\frac{1}{9 S_{a}}>0,
\end{aligned}
$$

which suggests that like the dominant funder $i$, the fringe funder $j$ provides more funding for disease with a greater burden and/or scientific knowledge (Hypothesis ??).

Next we examine how the funding support from funder $j$ responds to a positive shock to the budget of funder $i$. From equation ?? and ?? we have:

$$
\begin{aligned}
& \frac{\partial x_{a}^{j *}}{\partial Y^{i}}=-2 \frac{\partial x_{a}^{i *}}{\partial Y^{i}}+\frac{\partial x_{b}^{i}}{\partial Y^{i}}=-\frac{1}{3}<0 \\
& \frac{\partial x_{b}^{j *}}{\partial Y^{i}}=-2 \frac{\partial x_{b}^{i *}}{\partial Y^{i}}+\frac{\partial x_{a}^{i}}{\partial Y^{i}}=-\frac{1}{3}<0 .
\end{aligned}
$$

In other words, a positive shock to the budget of funder $i$ would induce lower funding support for both disease $a$ and $b$ from funder $j$ through increasing funding support from funder $i$ itself.

Finally, we show why we need an instrumental variable for identification. Consider a global economic shock that increases the budget of both funder $i$ and funder $j$. For simplicity, we assume that the budget of funder $i$ increases one unit, and the budget of funder $j$ increases two units. In this case, the overall changes in $x_{a}^{i *}$ and $x_{b}^{i *}$ are

$$
\begin{aligned}
& \frac{\partial x_{a}^{i *}}{\partial Y^{i}}=\frac{1}{3}>0 \\
& \frac{\partial x_{b}^{i *}}{\partial Y^{i}}=\frac{1}{3}>0 .
\end{aligned}
$$


Accordingly, the overall changes in $x_{a}^{j *}$ and $x_{b}^{j *}$ are

$$
\begin{aligned}
& \frac{\partial x_{a}^{j *}}{\partial Y^{j}}+\frac{\partial x_{a}^{j *}}{\partial Y^{i}}=\frac{2}{3}-\frac{1}{3}=\frac{1}{3}>0 \\
& \frac{\partial x_{b}^{j *}}{\partial Y^{j}}+\frac{\partial x_{a}^{j *}}{\partial Y^{i}}=\frac{2}{3}-\frac{1}{3}=\frac{1}{3}>0 .
\end{aligned}
$$

Thus, the shock increases funding support for disease $a$ and $b$ globally. As a result, $x_{a}^{i *}$ and $x_{a}^{j *}\left(x_{b}^{i *}\right.$ and $\left.x_{b}^{j *}\right)$ would be positively correlated in the data, contrary to the theoretical prediction, as displayed in equation ??. Hence, we need an instrumental variable that affects the outlays of only one funder. 